\title{
ANALISIS NILAI KARAKTER RELIGIUS DAN RASA INGIN TAHU DALAM BUKU AJAR KIMIA KELAS X PADA MATERI STRUKTUR ATOM
}

\author{
Nurhabibah*1, Ratih Permana Sari $^{2}$, dan Nurhafidhah ${ }^{3}$ \\ ${ }^{1,2,3}$ Program Studi Pendidikan Kimia, FKIP Universitas Samudra \\ Jln. Kampus Meurandeh, Langsa 24416 \\ *E-mail: nbibah45@gmail.com
}

\begin{abstract}
Abstrak
Penelitian ini bertujuan untuk mengetahui kemunculan nilai-nilai karakter religius dan rasa ingin tahu dalam buku ajar kimia di SMA kelas $\mathrm{X}$ pada materi struktur atom. Penelitian ini menggunakan pendekatan kualitatif dengan jenis penelitian analisis konten. Subjek penelitian ini adalah guru kimia SMA Negeri kota Langsa, yaitu SMA Negeri 2 Langsa, SMA Negeri 3 Langsa, SMA Negeri 4 Langsa dan SMA Negeri 5 Langsa. Penelitian ini menggunakan metode deskriptif dengan teknik survey. Teknik pengumpulan data dilakukan dengan wawancara dan observasi. Kegiatan penelitian menggunakan teknik analisis yang terdiri dari 6 langkah yaitu unitizing (penentuan satuan), sampling (penentuan sampel), recording (perekaman atau pencatatan), reduksi (reduksi), inferring (penarikan kesimpulan) dan narrating (mendeskripsikan). Hasil penelitian menunjukan bahwa kemunculan nilai karakter religus dalam buku ajar kimia pada materi struktur atom sebanyak 11 kalimat dan kemunculan nilai karakter rasa ingin tahu sebanyak 12 kalimat. Penulis berharap agar pendidik dapat memilih buku ajar yang mengandung lebih banyak nilai-nilai karakter dalam kehidupan sehari-hari dan orang tua tidak menyerahkan seluruh pendidikan karakter kepada sekolah.
\end{abstract}

Kata kunci: Analisis, Buku Ajar, Karakter, Struktur Atom

\begin{abstract}
This study aims to determine the emergence of the values of religious character and curiosity contained in the chemistry textbook in high school class $X$ on the atomic structure material. This study uses a qualitative approach with the type of content analysis research. The subjects of this study were chemistry teachers at the Langsa State Senior High School, namely SMA Negeri 2 Langsa, SMA Negeri 3 Langsa, SMA Negeri 3 Langsa, SMA Negeri 4 Langsa and SMA Negeri 5 Langsa. This research uses descriptive method with survey technique. Data collection techniques were carried out by interview and observation. Research activities use analytical techniques consisting of 6 steps, namely unitizing (determination of units), sampling (determination of samples), recording (recording or recording), reduction (reduction), inferring (drawing conclusions) and narrating (describes). The results showed that the emergence of religious character values in chemistry textbooks on atomic structure material was 11 sentences and the emergence of curiosity character values was 12 sentences. The author hopes that educators can choose textbooks that contain more character values in everyday life and parents do not hand over all character education to schools.
\end{abstract}

Keywords: Analysis, Textbook, Character, Atomic Structure 


\section{PENDAHULUAN}

Peraturan pemerintah dalam menetapkan Undang-Undang mengenai pembangunan karakter adalah untuk mewujudkan visi pembangunan nasional melalui terwujudnya hal yang luhur dan baik yang berdedikasi pada daya saing yang kuat, molaritas yang berdasarkan pancasila, pikiran terbuka dan bertaqwa kepada Tuhan Yang Maha Esa. Tujuan utama dari delapan misi yang ditujukan ialah untuk mendidik perilaku berdasarkan kemajuan teknologi dan standar yang berlaku. (Nurhafidhah, dkk., 2018).

Terbentuknya nilai karakter yang baik pada peserta didik dapat menjadi nilai lebih dalam menumbuh kembangkan generasi yang memiliki wawasan luas. Berdasarkan peraturan kementerian pendidikan nasional tahun 2010 menerapkan bahwa terdapat 18 nilai-nilai karakter yang telah dikembangkan dalam dunia pendidikan. Adapun 18 nilai karakter tersebut diantaranya ialah nilai religius, toleransi, mandiri, kerja keras, tanggung jawab dan lain sebagainya (Pupuh, dkk., 2017).

Nilai karakter dapat membantu mengurangi permasalahan yang sering terjadi di lingkungan sekitar. Menurut Sayekti (2013) terdapat beberapa permasalahan yang muncul di dalam tujuan dan fungsi pendidikan di lingkungan sekitar seperti kekerasan, kebocoran soal UN, tauran antar pelajar yang pada umumnya dapat merusak nama baik sekolah, keluarga dan sebagainya. Pengembangan karakter di dalam pendidikan dapat dikembangkan di dalam mata pelajaran salah satunya pada pelajaran kimia (Nurhafidhah, dkk., 2018).

Karakter dapat tumbuh dan berkembang di dalam diri peserta didik melalui kegiatan pembelajaran, salah satunya ialah pelajaran kimia (Ritonga, dkk., 2016). Salah satu sarana pembentukan nilai karakter yang dapat ditumbuhkan dalam pendidikan ialah melalui buku teks. Buku teks merupakan buku ajar yang memuat nilai-nilai pembentuk karakter peserta didik (Astuti dan Wuri, 2017). Hasil penelitian menunjukan bahwa terdapat beberapa buku ajar yang mengandung nilai karakter di dalamnya, antara lain yaitu nilai religius, jujur, disiplin, menghargai prestasi, kerja keras dan lain sebagainya yang terdapat pada buku ajar kimia kelas XI SMA/MA (Ritonga, dkk., 2016). Selain itu, nilai karakter lainnya seperti sikap sopan santun, rasa ingin tahu dan komunikasi juga dapat ditemui pada buku ajar kimia kelas XII SMA/MA (Ikhwani, 2018).

Kementrian Pendidikan dan Kebudayaan menerapkan peraturan pembentukan nilai karakter yang dapat dilakukan dalam satuan pendidikan, baik tingkat sekolah dasar maupun tingkat yang lebih tinggi. Hal ini telah tercantum dalam Undang-Undang Nomor 64 Tahun 2013. Karakter tersebut merupakan 18 nilai-nilai karakter yang sebaiknya ada di dalam buku ajar (Rahayuningtiyas dan Ali, 2018). Melalui kegiatan ini peneliti mencoba untuk menemukan 18 nilainilai karakter yang sebaiknya ada di dalam buku ajar terutama pada pelajaran kimia di SMA.

\section{METODE PENELITIAN}

Penelitian merupakan pendekatan kualitatif dengan jenis penelitian analisis konten. Kegiatan dilakukan dengan tujuan untuk menguraikan atau menjabarkan suatu objek yang akan diteliti atau dapat dikatakan dengan analisis konten. Pada penelitian ini peneliti menggunakan guru SMA Negeri 3 kota Langsa sebagai subjek 
dalam penelitian dan muatan nilai karakter yang terdapat dalam buku ajar kimia karangan Unggul Sudarmo tahun 2013 sebagai objek dalam penelitian. Data kegiatan survey dapat dikumpulkan dengan menggunakan teknik survey yang dapat menjelaskan peristiwa-peristiwa yang terjadi di lapangan. Penelitian ini dilakukan dengan menggunakan metode deskriptif. Menurut Arikunto (2016) penelitian deskriptif adalah suatu penelitian yang dilakukan tanpa menguji suatu hipotesis, melainkan menjabarkan apa adanya data dari suatu kegiatan penelitian.

Penelitian ini menggunakan Desain Triagulasi (triangulasi desain). Desain triangulasi merupakan suatu gambaran kegiatan penelitian yang dapat membahas topik yang sama dengan menggunakan pendekatan kualitatif dengan kuantitatif secara bersamaan (Sanjaya, 2013).

Teknik analisis data dalam penelitian ini terdiri dari beberapa langkah, yaitu (1) Unitizing (Penentuan Satuan), (2) Sampling (penentuan sampel), (3) Recording (perekaman atau pencatatan), (4) Reducing (reduksi), (5) Inferring (penarikan kesimpulan), (6) Narrating (mendeskripsikan) (Kippendroff dalam Astuti dan Wuri, 2017).

Penelitian ini menggunakan teknik survey dengan melakukan wawancara dan observasi. Menurut Sugiyono (2017) dalam penelitian kualitatif penentuan informan, menganalisis data, menafsirkan data atau membuat kesimpulan merupakan cara yang dapat dilakukan oleh peneliti itu sendiri sebagai human instrumen. Instrumen yang digunakan pada penelitian ini adalah lembar observasi dan pedoman wawancara.

Validitas data dari kegiatan penelitian dapat diperoleh dengan melakukan validitas dan reliabilitas. Validitas data yang digunakan dalam penelitian ini menggunakan validitas praktisi dan validitas semantik yang bertujuan untuk mengetahui data mana yang terinterpretasikan sesuai dengan konteksnya (Astuti dan Wuri, 2017).

Reliabilitas yang digunakan yaitu stabilitas dan replikabilitas. Stabilitas merupakan salah satu cara untuk mendapatkan data nilai karakter yang konsisten dalam buku ajar kimia karangan Unggul Sudarmo tahun 2013. Replikabilitas digunakan dengan menganalisis dokumen. Reliabilitas replikabilitas dilakukan dengan suatu diskusi atau konfirmasi dengan para ahli pakar untuk mendapatkan masukan terhadap analisis yang dilakukan. Data kemudian divalidasi kembali oleh guruguru kimia SMA kelas $\mathrm{X}$ yang menggunakan buku ajar kimia karangan Unggul Sudarmo tahun 2013 tersebut sebagai validasi praktisi. Hal tersebut dilakukan agar data yang diperoleh lebih akurat dan tepat.

Penelitian ini merupakan suatu peenelitian deskriptif yang bertujuan untuk menganalisis, merangkaikan atau menggambarkan suatu peristiwa bagaimana adanya pada penelitian dilakukan. Penelitian deskriptif digunakan untuk mendeskripsikan atau menjelaskan muatan nilai karakter yang terdapat dalam buku ajar kimia kelas $\mathrm{X}$ pada materi struktur atom (Arikunto, 2016).

\section{HASIL DAN PEMBAHASAN}

Karakter merupakan salah satu sikap kepribadian seseorang yang berasal dari bawaan hati, sifat kepribadian, perilaku kepribadian, perangai seseorang atau tempramen (Rosyad, 2019).

Pendidikan karakter dapat membentuk nilai-nilai positif pada diri 
seseorang seperti sikap tanggung jawab maupun bentuk perilaku yang baik. Salah satu sarana penerapan nilai karakter di sekolah dapat menggunakan buku ajar yang telah dipilih sesuai dengan standar dan ketetapan kurikulum yang berlaku (Sukiyat, 2020).

Salah satu buku ajar yang dapat digunakan sebagai sumber informasi terutama bagi menengah atas ialah buku ajar kimia. Pada penelitian ini telah dilakukan analisis nilai karakter terhadap buku ajar kimia karangan Unggul Sudarmo kelas $\mathrm{X}$ yang digunakan di SMA Negeri 3 Langsa analisis khusus dilakukan pada bab materi struktur atom.

Pendidikan karakter adalah suatu sistem untuk menanamkan nilai karakter, termasuk semua pemangku kepentingan dalam pendidikan, termasuk kurikulum, proses pembelajaran dan evaluasi, manajemen sekolah, peningkatan sarana dan prasarana. Menurut Astutu dan Wuri (2017) pendidikan nasional bertujuan untuk meningkatkan potensi peserta didik agar beriman kepada Tuhan Yang Maha Esa, bertawakal, berilmu, cakap dan tanggung jawab.

Hasil wawancara terhadap guru kimia yaitu ibu (TS) mengenai pendidikan nilai karakter di SMA Negeri 3 Langsa dapat diketahui bahwa, nilai karakter yang terdapat di dalam mata pelajaran merupakan hal yang sangat bagus dalam mendukung perkembangan zaman yang semakin maju.

Salah satu pembentukan nilai karakter di SMA Negeri 3 Langsa dapat dikembangkan melalui buku ajar yang termuat nilai-nilai karakter di dalamnya. Salah satu buku ajar yang termuat nilai karakter di dalamnya ialah buku ajar kimia karangan Unggul Sudarmo tahun 2013. Buku ajar kimia karangan Unggul Sudarmo merupakan buku yang telah sesuaikan oleh ketetapan kurikulum yang berlaku di sekolah. Keberadaan nilai karakter di dalam buku ajar dapat di jumpai pada setiap pengantar bab yang disajikan. Nilai karakter dalam buku ajar, tidak memiliki pengaruh besar dalam pengembangan karakter anak didik. Pengembangan nilai karakter dapat lebih dibentuk dengan cara mendidik dengan menerapkan contoh teladan yang baik.

Nilai karakter yang di bentuk pada peserta didik dapat dilakukan dengan adanya bimbingan maupun arahan yang menunjukan bahwa dalam suatu materi yang diajarkan terdapat nilai karakter di dalamnya. Berikut cuplikan gambar buku ajar kimia karangan Unggul Sudarmo tahun yang memfasilitasi siswa dalam buku yang memfasilitasi siswa menerapkan nilai-nilai karakter.

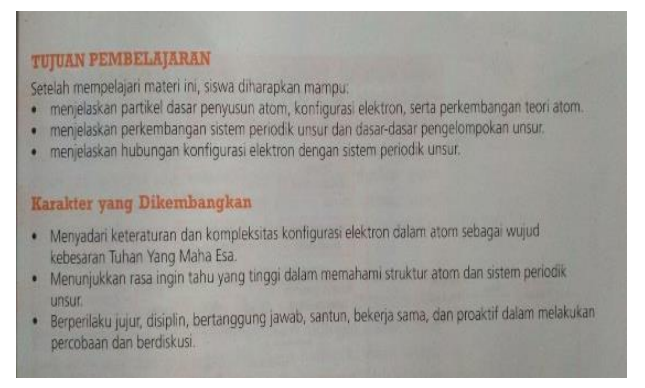

Gambar 1. Cuplikan Buku Ajar Unggul Sudarmo, (Sumber: Sudarmo, 2013: 27)

Gambar 1 menunjukan bagian buku ajar yang telah memfasilitasi siswa untuk menerapkan kepribadian karakter yang diajarkan. Nilai karakter tersebut adalah nilai religius, rasa ingin tahu, jujur, disiplin bertanggung jawab, santun bekerja sama dan proaktif. Kemunculan nilai karakter tersebut tidak dapat diketahui pada setiap sub materi yang telah disajikan. Maka dari itu, dilakukannya analisis lebih lanjut untuk mengetahui keberadaan nilai-nilai karakter yang ada di dalamnya. 
Berdasarkan hasil analisis data yang telah dilakukan, berikut adalah kemunculan nilai-nilai karakter di dalam buku ajar kimia karangan Unggul Sudarmo (2013) pada materi struktur atom.

Tabel 1. Muatan nilai karakter dalam buku ajar kimia Unggul Sudarmo pada materi struktur atom.

\begin{tabular}{|c|c|c|}
\hline No. & $\begin{array}{c}\text { Nilai } \\
\text { Karakter }\end{array}$ & $\begin{array}{c}\text { Jumlah } \\
\text { kemunculan }\end{array}$ \\
\hline 1. & Religius & 11 kalimat \\
\hline 2. & Jujur & 2 kalimat \\
\hline 3. & Toleransi & 5 kalimat \\
\hline 4. & Disiplin & 2 kalimat \\
\hline 5. & Kerja keras & 7 kalimat \\
\hline 6. & Kreatif & 4 kalimat \\
\hline 7. & Mandiri & 3 kalimat \\
\hline 8. & Demokratis & 3 kalimat \\
\hline 9. & $\begin{array}{c}\text { Rasa Ingin } \\
\text { Tahu }\end{array}$ & 12 kalimat \\
\hline 10. & $\begin{array}{c}\text { Semangat } \\
\text { kebangsaan }\end{array}$ & 0 \\
\hline 11. & $\begin{array}{c}\text { Cinta tanah } \\
\text { air }\end{array}$ & 0 \\
\hline 12. & $\begin{array}{c}\text { Menghargai } \\
\text { prestasi }\end{array}$ & 4 kalimat \\
\hline 13. & $\begin{array}{c}\text { Bersahabat/ } \\
\text { komunikatif }\end{array}$ & 2 kalimat \\
\hline 14. & Cinta damai & 3 kalimat \\
\hline 15. & $\begin{array}{c}\text { Gemar } \\
\text { membaca }\end{array}$ & 3 kalimat \\
\hline 16. & $\begin{array}{c}\text { Peduli } \\
\text { lingkungan }\end{array}$ & 2 kalimat \\
\hline 17. & Peduli sosial & 2 kalimat \\
\hline 18. & $\begin{array}{c}\text { Tanggung } \\
\text { jawab }\end{array}$ & 7 kalimat \\
\hline
\end{tabular}

Tabel 1. Menunjukan bahwa kemunculan nilai karakter rasa ingin tahu dan religius paling banyak ditemui pada materi struktur atom. Pemahaman dalam konteks kalimat yang mengandung nilai karakter tersebut dapat disesuaikan dengan indikator yang disajikan. Berikut beberapa cuplikan gambar yang mengandung nilai karakter dalam buku ajar kimia pada materi struktur atom.

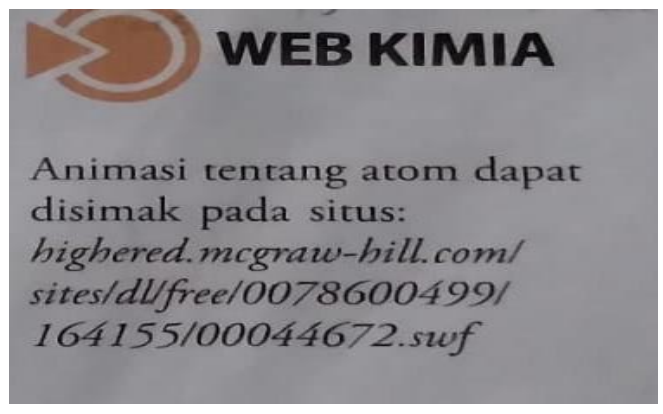

Gambar 2. Cuplikan isi buku ajar yang memfasilitasi siswa menerapkan nilai karakter rasa ingin tahu, (Sumber: Sudarmo, 2013)

Dari cuplikan isi buku ajar pada Gambar 2 menunjukan bahwa buku ajar karangan Unggul Sudarmo telah memfasilitasi siswa untuk memiliki nilai rasa ingin tahu. Nilai karakter muncul pada info kimia. Saat peserta didik mengakses dan membaca situs web yang terdapat di dalam bagian materi, peserta didik akan memiliki rasa ingin tahu dan penasaran mengenai hal apa yang dapat ditemui dari isi link yang disajikan pada buku ajar tersebut.

Karakter rasa ingin tahu merupakan cara berpikir, sikap dan perilaku yang mencerminkan penasaran dan keingintahuan terhadap segala hal yang dilihat, didengar, dan dipelajari secara lebih mendalam. Nilai karakter rasa ingin tahu adalah titik awal dari pengetahuan yang dimiliki oleh manusia sikap baik dari ketertarikan, mencari informasi mengenai sesuatu yang baru serta motivasi intrinsik seseorang terhadap pengetahuan maupun pengalaman baru (Hidayat, 2018). Selain kemunculan nilai karakter rasa ingin tahu yang paling banyak ditemui pada buku ajar, nilai karakter religius 
juga merupakan salah satu nilai yang banyak ditemui. Berikut cuplikan gambar nilai karakter religius dalam buku ajar.

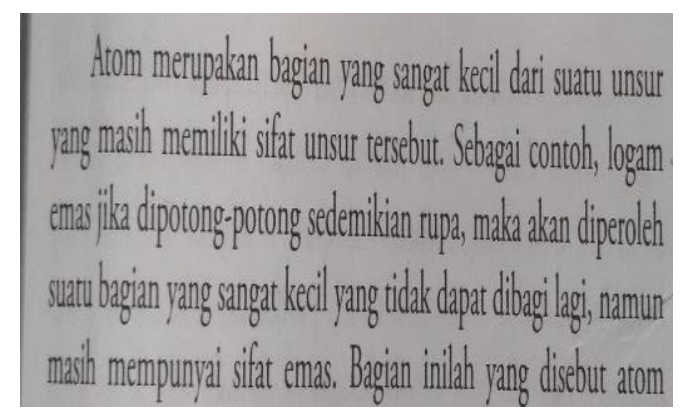

Gambar 3. Cuplikan isi buku ajar yang memfasilitasi siswa menerapkan nilai karakter religius (Sumber: Sudarmo, 2013)

Nilai karakter religius dalam cuplikan Gambar 3 terdapat pada kalimat "atom merupakan bagian yang sangat kecil dari suatu unsur yang masih memiliki sifat unsur tersebut. Sebagai contoh, atom emas. Atom emas berbeda jenisnya dengan atom perak, atom aluminium, atau atom besi". Kalimat tersebut memfasilitasi siswa untuk bersikap atau berperilaku religius dengan menyadari ciptaan Allah. Atom merupakan suatu bentuk kebesaran Allah, dimana manusia dan ilmuwan tidak dapat menciptakannya.

Dari cuplikan isi buku ajar tersebut menunjukan bahwa buku ajar karangan Unggul Sudarmo telah memfasilitasi siswa untuk berperilaku religius. Nilai karakter muncul pada bagian atom. Saat peserta didik membaca tentang atom baik jenis maupun sifat dan ukurannya, peserta didik akan menyadari bahwa atom merupakan ciptaan Allah SWT dimana hingga saat ini tidak ada satupun manusia bahkan ilmuwan yang menciptakannya.
Selain pada buku ajar kimia, kegiatan analisis buku ajar juga dilakukan pada peneliti sebelumnya oleh Ridwan dan Alif (2017: 4) menemukan nilai karakter religius pada buku siswa kelas IV sekolah dasar sebanyak $28 \%$ dimana nilai-nilai karakter religius adalah sikap dan tindakan yang menunjukan ketaatan terhadap ajaran agamanya, toleransi terhadap agama lain, dan upaya yang dapat meningkatkan taraf hidupnya dan tidak menyimpang dari ajaran agama yang dianutnya.

Penerapan nilai karakter dapat membantu peserta didik untuk menghadapi hambatan dan masalah baik di dalam maupun di luar sekolah. Adanya kesempatan yang diberikan sekolah dalam menerapkan nilai-nilai karakter dapat dikembangkan ke dalam Rencana Pendidikan, Jadwal dan Rencana Program Pembelajaran (RPP) (Hakim, 2014).

\section{KESIMPULAN}

Berdasarkan hasil penelitian dapat disimpulkan bahwa terdapat beberapa nilai-nilai karakter yang muncul pada buku ajar kimia kelas X pada materi struktur atom diantaranya ialah nilai karakter religius, jujur, toleransi, disiplin, kerja keras, kreatif, mandiri, demokratis, rasa ingin tahu, menghargai prestasi, bersahabat/ komunikatif, cinta damai, gemar membaca, peduli lingkungan, peduli sosial dan tanggung jawab. Dari hasil seluruh kemunculan nilai karakter di dalam buku ajar kimia kelas X pada materi struktur atom, nilai karakter yang paling banyak muncul dalam buku ajar kimia pada materi struktur atom ialah nilai rasa ingin tahu sebanyak 12 kalimat dan nilai karakter religius sebanyak 11 kalimat di dalamnya. 


\section{UCAPAN TERIMA KASIH}

Terimakasih kepada dosen pembimbing, dosen pendidikan kimia, mahasiwa pendidikan kimia serta SMA Negeri kota Langsa yang telah memberikan izin dalam melakukan kegiatan penelitian.

\section{DAFTAR PUSTAKA}

Arikunto, S. 2016. Prosedur Penelitian Suatu Pendekatan Praktik. Jakarta: Rineka Cipta

Astuti, H. P. dan Wuri, W. 2017. Analisis Nilai-Nilai Karakter Pada Buku Guru dan Buku Siswa Kelas IV Semester 1 Sekolah Dasar. Jurnal Pendidikan Karakter. 2(1): 226-239

Hakim, D. 2014. Implementasi Pendidikan Budaya dan Karakter Bangsa dalam Kurikulum Tingkat Satuan Pendidikan (KTSP) di Sekolah. Religi: Jurnal Studi Islam. 5(2): 145-168.

Hidayat, W., Jamil, B, A. dan Mohd. I, B, H. 2018. Nilai Keutamaan Pengetahuan Dan Kebijaksanaan Dalam Konteks Pendidikan Karakter Bangsa. Jurnal Penelitian dan Evaluasi Pendidikan. 22(1): 83-91

Ikhwani. 2018. Pengembangan Buku Ajar Kimia Kelas XII SMA/MA Semester II Terinternalisasi Nilai Karakter Sesuai Dengan Kurikulum 2013. Lantanida Journal. 6(1): 40-48

Nurhafidhah., Yakob, M. dan Mauliza. 2018. Kajian Aspek Nilai Karakter Pada Buku Ajar IPA.
Katalis: Jurnal Penelitian Kimia dan Pendidikan Kimia. 1(01): $1-6$

Pupuh, F., Suryana. dan Fatriany. 2017. Pengembangan Pendidikan Karakter. Bandung: PT Refika Aditama

Rahayuningtiyas, D, I. dan Ali, M. 2018. Analisis Muatan Nilai Karakter Pada Buku Ajar Kurikulum 2013 Pegangan Guru Dan Siswa Sekolah Dasar. Jurnal Pendidikan Karakter. 8(2): 123-139

Ritonga, R., Ajat. dan Eddiyanto. 2016. Inovasi Buku Ajar Kimia SMA/MA Kelas XI Semester Ganjil Terinternalisasi NilaiNilai Karakter Siswa. Jurnal Pendidikan Kimia. 8(3): 152158

Rosyad, A, M. 2019. Implementasi Pendidikan Karakter melalui Kegiatan Pembelajaran di Lingkungan Sekolah. Tarbawi Jurnal Keilmuan Pendidikan. 5(02): 173-190

Sanjaya, W. 2013. Penelitian Pendidikan: Jenis, Metode dan Prosedur Edisi Pertama. Jakarta: Kencana

Sayekti, I. C, 2013. Peran Pembelajaran IPA di Sekolah dalam Membangun Karakter Anak, Prosiding Seminar Nasional dan Call for Papers dengan tema Aktualisasi Bimbingan dan Konseling pada Pendidikan Dasar Menuju Peserta Didik yang Berkarakter, 140-146.

Sudarmo, U. 2013. Kimia Untuk SMA/MA Kelas $X$. Jakarta: Erlangga 
Sugiyono. 2017. Metode Penelitian Kualitatif Untuk Penelitian Yang Bersifat: Eksploratif, Enterpretif, Interaktif dan Konstruktif. Bandung: Alfabeta

Sukiyat. 2020. Strategi Implementasi Pendidikan Karakter.

Surabaya: CV. Jakad Media Publishing 